\title{
AUDIT TATA KELOLA TEKNOLOGI INFORMASI MENGGUNAKAN FRAMEWORK COBIT 5 (STUDI KASUS: PT.INDOCOM TAMBAK UDANG LAMPUNG)
}

\author{
Ridho Anang Rizaldi \\ $1611059012 P$ \\ Fakultas Bisnis \& Komputer \\ IIB Darmajaya Lampung \\ Ridhoanang.1611059012@mail.darmajaya.ac.id
}

\begin{abstract}
Abstrak
PT.INDOCOM TAMBAK UDANG LAMPUNG adalah Unit Pelaksana Teknis (UPT) di bidang pengembangan budidaya udang yang berada di bawah dan bertanggungjawab kepada Direktorat Jendral Perikanan Budidaya PT.INDOCOM TAMBAK UDANG LAMPUNG merupakan telah menggunakan sistem e-SKP (elektronik Sasaran Kinerja Pegawai). Saat ini kegiatan tata kelola keamanan informasi belum dilakukan secara maksimal. Untuk mengantisipasi terjadinya kendala seperti sumber daya manusia yang kurang memahami aplikasi e-SKP sehingga berpotensi terjadinya error pada aplikasi, maka dilakukan metode pengelolaan teknologi informasi menggunakan kerangka kerja COBIT. Proses yang digunakan dalam penelitian ini adalah EDM03, APO13, APO12, BAI06, DSS01, DSS02, DSS03, DSS05, MEA01, MEA02. Analisis data menggunakan Maturity Level dan Analisis Kesenjangan untuk menentukan tingkat kematangan. Dari hasil nilai aktual dan nilai ekspektasi yang ditentukan, penulis mendapatkan gap dari analisis kesenjangan di atas.
\end{abstract}

Kata kunci : Tata Kelola Keamanan Informasi, Maturity Level, Analisis Kesenjangan, e-SKP, COBIT 5 


\section{PENDAHULUAN}

\section{A. Latar Belakang}

Dengan semakin berkembangnya teknologi, khususnya teknologi informasi dan komputer, maka banyak perusahaan yang mengadopsi sistem informasi berbasis komputer sebagai bagian penting dari kelancaran kegiatan operasi perusahaan tidak terkecuali pemerintahan. PT INDOCOM TAMBAK UDANG LAMPUG merupakan salah satu yang telah menerapkan teknologi informasi (TI) dalam bidang Sasaran Kinerja Pegawai (SKP) yaitu dengan menggunakan sistem e-SKP (elektronik Sasaran Kinerja Pegawai). Saat ini kegiatan tata kelola keamanan informasi belum dilakukan secara maksimal. Untuk mengantisipasi terjadinya kendala seperti sumber daya manusia yang kurang memahami aplikasi e-SKP sehingga berpotensi terjadinya error pada aplikasi, kemudian e-SKP masih menghadapi persoalan berkaitan dengan sering terjadi kehilangan data e-SKP dan belum ada solusi terkait masalah kehilangan data tersebut, maka perlu adanya audit tata kelola keamanan informasi untuk peningkatan keamanan data dan informasi pada Balai Besar Perikanan Budidaya Laut Lampung khususnya pada sistem e-SKP. Dalam bidang tata kelola teknologi informasi, terdapat sebuah kerangka kerja COBIT untuk mengukur kematangan pemanfaatan IT di sebuah organisasi. Kerangka COBIT 5 membagi proses teknologi informasi menjadi 5 domain, yaitu EDM (Evaluate, Direct and Monitor), APO (Align, Plan and Organise), BAI (Build, Acquire and Implement), DSS (Deliver, Service, and Support), MEA (Monitor, Evaluate and Assess) dengan keseluruhan 37 proses yang ada didalamnya. COBIT berfungsi untuk mempertemukan semua kebutuhan control dan isu-isu tekni, selain itu COBIT juga dirancang menjadi alat bantu untuk memecahkan permasalahan pada IT Governance dalam memahami dan mengelola resiko serta keuntungan yang berhubungan dengan sumber daya informasi.

Dengan dilakukannya audit tata kelola keamanan informasi menggunakan framework COBIT 5 akan memberikan informasi kepada PT INDOCOM TAMBAK UDANG LAMPUG mengenai hasil analisis yang akan digunakan untuk melakukan peningkatan terhadap sistem e-SKP (Elektronik Sasaran Kinerja Pegawai). Tujuan penelitian ini adalah untuk mengaudit keamanan informasi pada sistem e-SKP dengan menggunakan framework COBIT 5 dengan domain Evaluate Direct and Monitor (EDM), Align Plan and Organise (APO), Build Acquire and Implement (BAI), Deliver Service and Support (DSS), dan Monitor Evaluate and Assure (MEA) guna mengetahui tingkat keamanan informasi pada sistem e-SKP di Balai Besar Perikanan Budidaya Laut Lampung. Selain itu dilakukan pengujian terhadap sistem menggunakan aplikasi Nessus Scanner dan Apache Jmeter.

\section{B. Landasan Teori}

\section{Definisi Audit}

Audit pada dasarnya adalah proses sistematis dan obyektif dalam memperoleh dan mengevaluasi bukti-bukti tindakan ekonomi, guna memberikan asersi/pernyataan dan menilai seberapa jauh tindakan ekonomi sudah sesuai dengan kriteria yang berlaku dan mengkomunikasikan hasilnya kepada pihak terkait. 


\section{Tata Kelola Teknologi Informasi (TI)}

Tata kelola TI adalah :"Tata kelola

TI sebagai tanggung jawab eksekutif dan dewan direksi, sebagai bagian dari tata kelola bisnis terdiri atas kepemimpinan, struktur dan proses-proses organisasi, yang akan memastikan bahwa TI organisasi tersebut bisa mendukung dan menyampaikan tujuan strategis organisasi".

Pentingnya Tata Kelola Teknologi yaitu :

1. Adanya perubahan peran TI, dari peran efisiensi ke peran strategic yang harus ditangani level korporat.

2. Banyak proyek TI strategic yang penting namun gagal dalam pelaksanaanya karena

hanya ditangani oleh teknisi TI.

3. Keputusan TI di dewan direksi sering bersifat ad hoc atau tidak terencana dengan baik.

4. TI merupakan pendorong utama proses transformasi bisnis yang member imbas penting bagi organisasi dalam pencapaian misi, visi, dan tujuan strategic.

5. Kesukaan pelaksanaan TI harus dapat terukur melalui metric tata kelola TI.

\section{Tata Kelola Teknologi Informasi dan Manajemen Teknologi Informasi}

Tata Kelola Teknologi Informasi

dan Manajemen Teknologi Informasi memastikan

bahwa tujuan perusahaan tercapai dengan mengevaluasi pemangku kepentingan, kebutuhan,

kondisi dan pilihan. Menetapkan arah memalui prioritas dan pengambilan

keputusan, pemantauan kinerja, kepatuhan dan kemajuan terhadap arah dan tujuan.

Salah satu kunci fokus tata kelola teknologi informasi adalah untuk menyelaraskan teknologi informasi dengan tujuan bisnis. Sebagai penjelasan dapat dikatakan bahwa tata kelola teknologi informasi adalah perpaduan antara tata keloa perusahaan dan manajemen teknologi informasi.

\section{COBIT 5}

COBIT 5 (Control Objektives For Information and Related Technology) merupakan generasi terbaru dari panduan ISACA dibuat berdasarkan pengalaman penggunaan COBIT selama lebih dari 15 tahun oleh banyak perusahaan dan penggunaan dari bidang bisnis, komunitas, $I T$, risiko, asuransi, dan keamanan. COBIT 5 mendefinisikan dan menjelaskan secara rinci sejumlah tata kelola dan manajemen proses. COBIT 5 menyediakan kerangka kerja yang komprehensif yang membantu perusahaan dalam mencapai tujuan mereka untuk tata kelola dan manajemen aset informasi perusahaan dan teknologi (IT). Secara sederhana, membantu perusahaan menciptakan nilai yang optimal dari $I T$ dengan menjaga keseimbangan antara mewujudkan manfaat dan mengoptimalkan tingkat resiko dan penggunaan sumber daya. COBIT 5 menggunakan praktik tata kelola dan manajemen untuk menjelaskan tindakan praktik yang baik untuk efek tata kelola dan manajemen lebih perusahaan IT. COBIT 5 tidak dimaksudkan untuk menggantikan salah satu kerangka kerja atau standar lainnya, tetapi untuk menekankan tata kelola dan manajemen serta mengintegrasikan praktik pengelolaan terbaik pada perusahaan. COBIT 5, memiliki kriteria informasi asli yaitu : Efisiensi, Efektivitas, Kerahasiaan, Integritas, Ketersediaan, Kepatuhan, dan Kehandalan. 


\section{Prinsip Dasar COBIT 5}

COBIT 5 (Control Objectivies

Information and Related Technology)

secara umum memiliki 5 prinsip dasar yaitu [1]:

a. Meeting Stakeholder Needs

Terdapat usaha dari perusahaan untuk menciptakan nilai bagi para stakeholder dengan menjaga keseimbangan antara realisasi manfaat, optimalisasi risiko, dan penggunaan sumber daya.

b. Convering the Enterprise End-to-End Bermanfaat untuk menintegrasikan tata kelola TI perusahaan kedalam tata kelola perusahaan. Sistem tata keloa TI yang digunakan COBIT 5 dapat menyatu dengan sistem tata kelola perusahaan dengan lancar. Prinsip kedua ini dibutuhkan untuk mengatur dan mengelola TI perusahaan dimanapun informasi diproses, baik layanan TI internal maupun eksternal.

\section{c. Applying a Single Integrated}

Framework

Terdapat banyak standar yang berkaitan dengan IT, masing-masing memberikan panduan pada subset dari kegiatan IT. COBIT 5 sejalan dengan standar lain yang relevan dan kerangka pada tingkat tinggi. Dengan demikian, COBIT 5 dapat menjadi kerangka menyeluruh untuk tata kelola dan manajemen perusahaan.

d. Enalbling a Holistic Approach

Tata kelola dan manajemen perusahaan yang efektif dan efisien membutuhkan pendekatan holistic, dengan mempertimbangkan beberapa komponen yang saling berinteraksi.

e. Separating Governance From

Management

COBIT membuat perbedaan yang cukup jelas antara tata kelola dan manajemen.
Kedua hal tersebut mencakup berbagai kegiatan yang berbeda, memerlukan struktur organisasi yang berbeda, dan melayani untuk tujuan berbeda pula.

\section{Domain COBIT 5}

COBIT 5 framework dirancang dengan 5 domain yang masing-masing mencakup penjelasan rinci dan termasuk panduan secara luas dan bertujuan sebagai tata kelola dan manajemen TI perusahaan.

Lima domain yang ada pad COBIT 5 adalah :

a. EDM (Evaluate, Direct and Monitor)

b. APO (Align, Plan and Organise)

c. BAI (Build, Acquire and Implement)

d. DSS (Deliver, Service, and Support)

e. MEA (Monitor, Evaluate and Assess)

\section{Pengukuran Tingkat Kematangan (Maturity Level)}

Salah satu alat pengukur dari kinerja suatu sistem teknologi informasi adalah model kematangan (maturity level), model kematangan digunakan untuk mengontrol proses-proses teknologi informasi menggunakan framework COBIT dengan informasi menggunakan metode penilaian /scoring tujuannya adalah organisasi dapat mengetahui posisi kematangan teknologi informasi saat ini dan organisasi dapat terus menerus berkesinambungan berusaha meningkatkan levelnya sampai tingkat tertinggi agar aspek governance terhadap teknologi informasi dapat berjalan dengan lancar. 


\section{Audit Software}

Audit Softrware merupakan jenis software review dimana satu atau lebih auditor yang bukan anggota dari pengembang perangkat, di luar organisasi yang melakukan pemeriksaan inezpnden dari produk perangkat lunak, proses software untuk menilai sesuai dengan spesifikasi, standar, perjanjian kontrak atau kriteria lainnya. Tujuan audit software adalah untuk memberikan evaluasi independen dari kesesuaian produk perangkat lunak dan proses ketentuan yang berlaku, standar, pedoman, dan rencana. Prinsip audit software adalah sebagai berikut :

a. Ketepatan waktu

b. Open Source reflection

c. Bibliography

d. Referencing Innovations

e. Analysis of document

f. Scientific referencing and Learning

g. Continuous Review

h. Elaboration

\section{Apache Jmeter}

Apahe Jmeter adalah sebuah perangkat lunak open source, aplikasi java murni yang dirancang untuk memuat prilaku fungsional tes dan menukur kinerja dan mengukur kinerja. Apache Jmeter pada awalnya dirancang untuk menguji aplikasi web tetapi sekaran sudah dipeluas untuk menguji fungsional lainnya. Secara umum Apache JMeter adalah sebuah tools berikut :

yang memiliki fungsi sebagai

a. Sebuah Tool atau alat yang digunakan untuk melakukan performace test pada sebuah software.

b. Apache JMeter dapat memberikan request dalam jumlah yang sangat banyak secara bersamaan dalam satu waktu pada server

c. Apache JMeter dapat memberikan analisa dan Laporan dari hasil pengujian d. Berikut ini adalah requirement yang dibutuhkan untuk menjalankan Apache JMeter, yaitu :

e. JRE (Java Runtime Enviroment) >= 1.6

f. Operating Systems Unix (Solaris, Linux, etc), Windows (98, NT, XP, etc)

\section{Vulnerability scanner}

Vulnerability scanner adalah sebuah program komputer yang di desain untuk mencari dan memetakan system untuk kelemahan pada aplikasi, computer atau jaringan. Meningkatnya penggunaan internet membuat semakin banyaknya website yang bermunculan. Namun sangat disayangkan kejahatan internet terus meningkat seiring bermunculannya ragam artikel yang membahas masalah hacking. Tools yang digunakan untuk menganalisa kelemahan kelemahan 


\section{METODE PENELITIAN}

\section{A. Tahapan Penelitian}

Berikut tahapan penelitian yang digunakan, dapat dilihat pada gambar 1 berikut:

\section{B. Identifikasi Masalah}

Identifikasi masalah adalah tahapan selanjutnya setelah menentukan topik penelitian dari beberapa pilihan topik yang telah disediakan. Tahapan ini dilakukan untuk mendapatkan informasi mengenai permasalahan yang terjadi di PT INDOCOM TAMBAK UDANG LAMPUG terkait audit tata kelola sistem informasi.

\section{IDENTIFIAS}

\section{PENGUMPU}

HASIL DAN PEMBAHASAN

Tahapan Penelitian

\section{ANALISIS}

\section{Pengumpulan Data}

Penelitian ini dilakukan melalui
PENGUPULAN

BUKTI
Studi ini mengukur kematangan yang terjadi di lembaga-lembaga dalam rangka mencapai tujuan institusional 5. Penelitian ini merupakan penelitian studi kasus di mana lokasi penelitian ini di PT INDOCOM TAMBAK UDANG LAMPUG. mengendalikan proses teknologi informasi didasarkan pada COBIT framework versi deskriptif, penelitian ini terdiri dari data primer dan sekunder. Data primer diperoleh dari wawancara dan sistem operator yang didasarkan pada instrumen penelitian dengan menggunakan kuisioner, survei dan observasi pada implementasikan teknologi informasi.

\section{Analisis Data}

Setelah dilakukan pengumpulan data, penulis melakukan analisis data. Analisis data yang dilakukan terdiri dari analsisi tingkat kematangan dan analsisi kesenjangan. Pengolahan dan dana analsisi hasil penelitian dilakukan dengan sistem komputerisasi Microsoft Excel 2010. 


\section{Analisis Tingkat Kematangan saat ini}

Dari hasil jawaban kuisioner dan

hasil wawancara dari narasumber pada instansi balai yang diperoleh saat melakukan analisis tersebut. Analisis yang dilakukan pada tahap ini adalah untuk menilai tingkat kematangan tata kelola teknologi informasi saat ini, akan tersedia jawaban dengan nilai 0-5.

\section{Analisis Tingkat Kematangan yang diharapkan}

Setelah melakukan analisis kematangan saat ini, penulis melakukan analisis tingkat kematangan yang diharapkan

\section{Analisis Kesenjangan $(G A P)$}

Setelah tingkat kematangan saat ini dan tingkat kematangan yang diharapkan diperoleh, penulis akan melakukan analisis kesenjangan terhadap tingkat kematangan tersebut.

\section{Pengumpulan Bukti}

Pada tahap ini peneliti melakukan pengumpulan bukti untuk menunjukkan adanya kekurangan di dalam sistem eSKP, pengumpulan bukti ini dilakukan dengan bantuan tools audit yaitu Nessus 6.1 dan tools testing adalah Apache Jmeter. Tools Nessus berfungsi sebagai alata untuk mengaudit kerentanan sebuah sistem aplikasi berbasis website. Nessus memberikan secara detail kerentanan yang bisa terjadi di sebuah sistem dan memberikan solusi terhadap kerentanan tersebut. Tools testing Apache Jmeter merupakan merupakan

Kependekan dari Web Application Load, Stress, and Performance Testing) atau berarti aplikasi untuk melakukan test load, stress, dan performa pada sebuah alat aplikasi website. Hasil output berupa daftar table dan grafik yang menunjukkan tingkat peforma, tingkat stress, tingkat error dari sebuah aplikasi website

\section{Identifikasi Domain dan Proses COBIT 5 Berdasarkan IT Related Goals} selanjutnya melakukan pemilihan terhadap 5 Domain dan 37

Proses COBIT 5 berdasarkan matriks berikut ini:

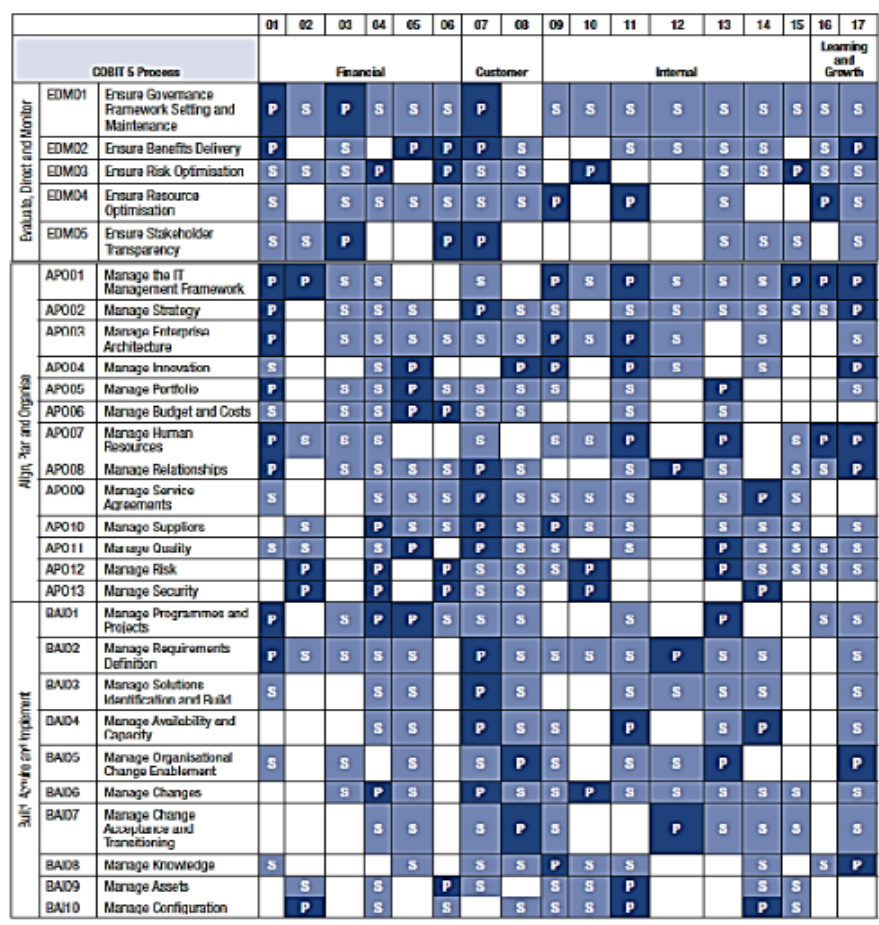

Matrik Domain COBIT 5 dan IT Related Goals 
Dari matrik tersebut dapat disimpulkan domain dan proses COBIT 5 yang akan digunakan ialah:

\begin{tabular}{|l|l|l|}
\hline No & Domain & Keterangan \\
\hline 1 & AP010 & Mengelola Penyedia \\
\hline 2 & APO12 & Mengelola Risiko \\
\hline 3 & AP013 & Mengelola Keamanan \\
\hline 4 & BAI01 & Mengelola Program dan Proyek \\
\hline 5 & BAI06 & Mengelola Perubahan \\
\hline 6 & DSS01 & Mengelola Operasi \\
\hline 7 & DSS02 & $\begin{array}{l}\text { Mengelola Permintaan Layanan dan } \\
\text { Insiden }\end{array}$ \\
\hline 8 & DSS03 & Mengelola Masalah \\
\hline 9 & DSS04 & Mengelola Kelangsungan \\
\hline 10 & DSS05 & Mengelola Layanan Keamanan \\
\hline 11 & DSS06 & Mengelola Kendali Proses Bisnis \\
\hline 12 & EDM03 & Memastikan Optimasi Risiko \\
\hline 13 & MEA01 & $\begin{array}{l}\text { Memantau, Melakukan Evaluasi } \\
\text { dan Menilai Kinerja dan Kesesuaian }\end{array}$ \\
\hline 14 & MEA02 & $\begin{array}{l}\text { Memantau, Melakukan Evaluasi } \\
\text { dan Menilai Sistem dari Kendali } \\
\text { Internal }\end{array}$ \\
\hline 15 & MEA03 & $\begin{array}{l}\text { Memantau, Melakukan Evaluasi } \\
\text { dan Menilai Kepatuhan dengan }\end{array}$ \\
\hline
\end{tabular}

\section{HASIL DAN PEMBAHASAN}

\section{A. Analisis Kesenjangan}

\begin{tabular}{|l|l|l|l|}
\hline \multirow{2}{*}{ Proses } & \multicolumn{3}{|l|}{ Tingkat Kematangan } \\
\cline { 2 - 4 } & Saat Ini & Diharapkan & GAP \\
\hline EDM03 & 2,9 & 4 & $4,0-2,9=1,1$ \\
\hline AP012 & 2,9 & 4 & $4,0-2,9=1,1$ \\
\hline AP013 & 2,7 & 4 & $4,0-2,7=1,3$ \\
\hline BAI06 & 2,6 & 4 & $4,0-2,6=1,4$ \\
\hline DSS01 & 2,7 & 4 & $4,0-2,7=1,3$ \\
\hline DSS02 & 2,8 & 4 & $4,0-2,8=1,2$ \\
\hline DSS03 & 2,8 & 4 & $4,0-2,8=1,2$ \\
\hline DSS05 & 2,7 & 4 & $4,0-2,7=1,3$ \\
\hline MEA01 & 2,8 & 4 & $4,0-2,8=1,2$ \\
\hline MEA02 & 2,9 & 4 & $4,0-2,9=1,1$ \\
\hline Rata-rata & & 1,2 \\
\hline
\end{tabular}

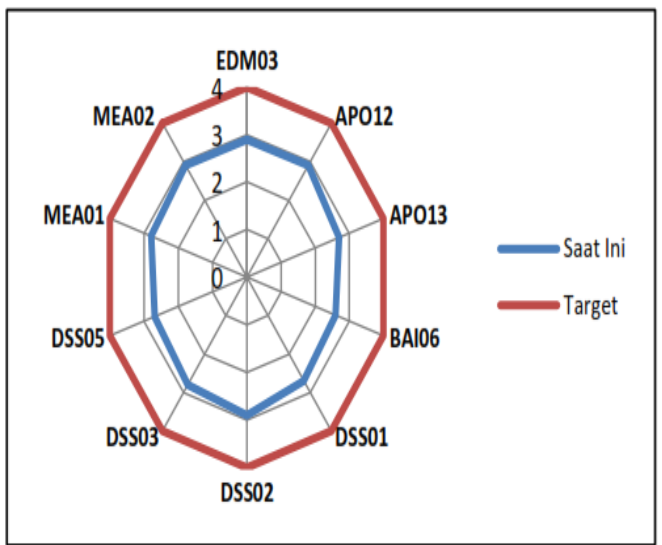

Kesenjangan masing - masing pro Dari grafik diatas dapat dilihat kesenjangan dari masing-masing proses, kesimpulan dari spider chart

diatas adalah kesepuluh proses COBIT 5 belum ada yang sesuai dengan target yaitu 4,0. dari sepuluh proses 
B. Pengujian Vulnerability terhdapat Sistem ESKP

Hasil dari analisa vulnerability terhadap sistem e-SKP dapat diketahui beberapa kelemahan-kelemahan yang bisa menjadi pintu masuk bagi attacker untuk menguasai sistem e-SKP. Hasil yang

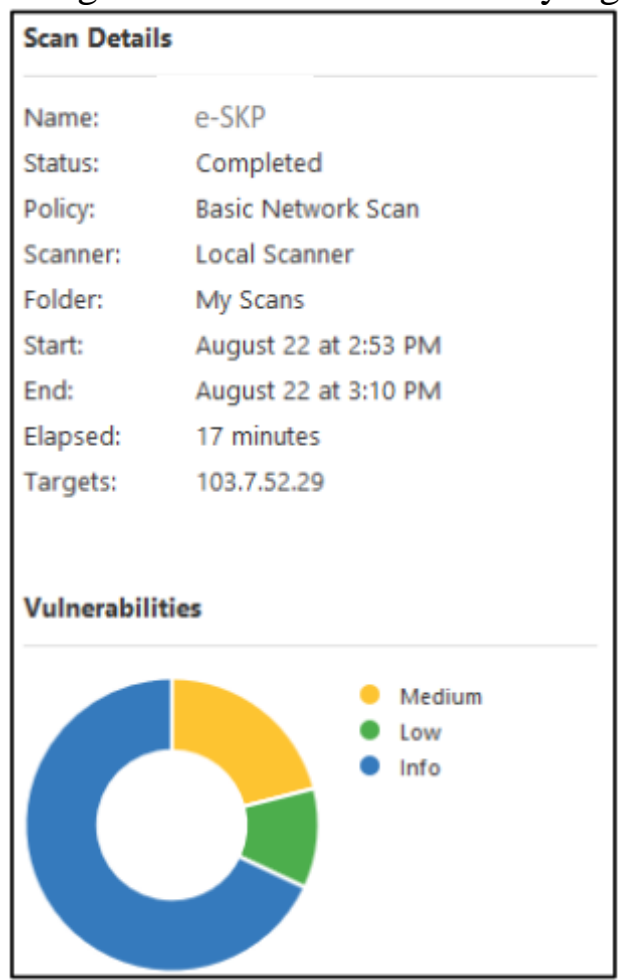

Detail Hasil Scanner Menggunakan Nessus ditunjukkan Nessus Scanner dapat diketahui terdapat 45 jenis kelemahan terdiri dari berbagai kategori yakni mediun dan info.

Pada gambar 3 di bawah ini ditunjukkan hasil dari Nessus Scanner

Dari gambar 4 dapat diketahui jenis kelemahan dengan rincian sebagi berikut :

a. Kategori medium sebanyak 8 kelemahan

b. Kategori low sebanyak 4 kelemahan

c. Kategori info sebanyak 33 kelemahan 


\section{Hasil Pengujian sistem e-SKP menggunakan Apache Jmeter}

Pengujian menggunakan Apache

Jmeter terhadap sistem e-SKP. Apache

Jmeter menguji sistem dengan cara

menjalankan 50 virtual user. Secara

bertahap dengan jumlah perulangan 2 kali.

Dalam Test Ini didapat throghput server

prestasikerja.kkp.go.id adalah

102.366/menit artinya server

prestasikerja.kkp.go.id dapat menangani

permintaan 102.366/menit. Deviasi

prestasikerja.kkp.go.id adalah 3781

dibandingkan dengan devisasi server

google yaitu (577) dengan nilai deviasi

\section{DAFTAR PUSTAKA}

[1] Anggoro A D., 2014. Analisis Kepatuhan Karyawan Terhadap Kebijakan Pengamanan Data pada PT XYZ dengan Standar COBIT 5, Program Studi

Teknik Informatika Universitas Bakrie, Jakarta.

[2] Handayaningsih S., 2013. Perancangan Model Tata Kelola Teknologi Informasi Berbasis Cobit 4.1

pada Proses Mengelola Sumber Daya Manusia IT (Studi Kasus Bagian Pengelolaan Data Kab,

Kendal),Program Studi Teknik Informatika

Universitas

Ahmad Dahlan, Yoyakarta.
3781 yang besar maka dapat disimpulkan peforma sistem e-SKP kurang baik dan perlu ditingkatkan kembali. Hasil tersebut diperoleh dari 50 sampel user (Virtual) dengan rata-rata waktu respon yang dibutuhkan untuk mengakses sistem eSKP adalah 797 ms, waktu respon yang paling cepat adalah $429 \mathrm{~ms}$ dan waktu respon paling lama adalah $5715 \mathrm{~ms}$. Error yang ditemukan pada testing ini adalah $0 \%$.

[3] Masykur Fauzan., 2015. Analisis Vulnerability Web

Based Application menggunakan Nessus, Fakultas Teknik Universitas Purwokerto.

[4] Megawati.,2014. Evaluasi Tingkat Kematangan Teknologi Informasi Dengan Menggunakan Model Maturity Level COBIT 4.1 di PT BRI Cabang Bangkinang, Program Studi Sistem Informasi Universitas Islam Negeri Suska Riau Jalan HR. Soebrantas KM 115 Tampan Pekanbaru, Riau.

[5] Putra R., 2015. Evaluasi Tata Kelola Teknologi Informasi Berbasis COBIT 5 dalam Pelayanan Sistem

Informstasi Akademik di Universitas Pendidikan Ganesha, Program Studi Magister Teknik Informatika

Program Pascasarjana Universitas Atmajaya Yogyakarta, Yogyakarta. 